\title{
Research Paper: Development of a Methodology to Identify Crucial Emergency Stations for Quick Relief crossuark Response to the Damaged Urban Areas Following an Earthquake (Case Study: Isfahan City Center)
}

\author{
Seyed Ahmad Almasi ${ }^{1}$, Mohammad Mehdi Khabiri ${ }^{1 *}$, Mehdi Fallah Tafti ${ }^{1}$, Meisam Akbarzadeh \\ 1. Department of Civil Engineering, Faculty of Engineering, Yazd University, Yazd, Iran. \\ 2. Department of Transportation Engineering, Isfahan University of Technology, Isfahan, Iran.
}

\begin{tabular}{l|l}
$\begin{array}{c}\text { Use vour devic to scan } \\
\text { and read the article online }\end{array}$ \\
Crtation:Almasi SA, Khabiri MM, Fallah Tafti M, Akbarzadeh M. Development of a Methodology to Identify Crucial Emer- \\
gency Stations for Quick Relief Response to the Damaged Urban Areas Following an Earthquake (Case Study: Isfahan City \\
Center). Health in Emergencies and Disasters Quarterly. 2018; 3(3): 131-142. https://doi.org/10.29252/NRIP.HDQ.3.3.131 \\
dol: $:$ https://doi.org/10.29252/NRIP.HDQ.3.3.131
\end{tabular}

Article info:

Received: 19 Sep. 2017

Accepted: 16 Feb. 2018

\section{Keywords:}

Transportation, Crisis management, Important medical centers, Urban area vulnerability, GIS

\begin{abstract}
Background: By identifying the geographical location for the crucial relief stations, it is possible to facilitate the accessibility of the medical services to the injured individuals in crisis situations. The main objective of this research is to study the possibility of combined application of the Analytical Hierarchy Process (AHP), ArcGIS and Transcad software to identify the factors which affect the vulnerability of infrastructure in a study region, to determine the relative importance of these factors in relation to each other, to identify the high risk regions, to identify appropriate health-care centers for relief purposes and to examine the capability of these centers for providing the services required in crisis conditions.
\end{abstract}

Materials and Methods: This is a case study type of research, conducted in the central region of Isfahan, a large city located in the middle of Iran. The required data and information have been collected from the results of the "Population and Housing Census" comprising maps presenting the current status of Isfahan. They were then analyzed using Arc GIS and Transcad software and an AHP model developed by using the Expert Choice Software.

Results: The obtained results revealed the possibility of successful application of the methodology proposed in this study. The results of this case study, conducted on 94 out of 186 traffic zones defined in the "Comprehensive Transportation Plan of Isfahan City," indicated that 10 zones, mainly located in the residential areas, are highly vulnerable to be exposed to the post-earthquake incidents. The results also showed that out of 19 medical centers located at the service area of the study region, which also contribute to the $80 \%$ of the medical services in Isfahan, four medical centers with the best accessibility in the shortest time, can provide services to these 10 zones.

Conclusion: The results obtained from this case study indicated that the vulnerability of a traffic zone and its fatality rate in crisis events cannot be specified by only considering its physical conditions and other factors, e.g., population density and building density but also the lifetime of the buildings are also highly effective. In addition, due to the inappropriate positioning and being located in the narrow and vulnerable streets, some of the medical stations, such as Hojatieh Hospital and Amir-Al-Muminin Hospital, are vulnerable to postcrisis risk and there is a possibility of loss of access to these centers.

* Corresponding Author:

Mohammad Mehdi Khabiri, PhD

Address: Department of Civil Engineering, Faculty of Engineering, Yazd University, Yazd, Iran.

E-mail:mkhabiri@yazd.ac.ir 


\section{Introduction}

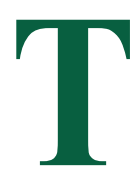

he term "Crisis" refers to the existence of an abnormal condition, a situation that the society does not experience under normal conditions. Following a crisis (e.g. an earthquake), the follow-up events related to the defects in the infrastructure and their operations could amplify the criticality of the situation. Therefore, crisis management should not be considered as a system activated to respond during the crisis, but it should be evaluated as a preventive activity and pre-crisis readiness [1]. If the prediction of the main route of the relief vehicles is not done accurately, it would lead to a crisis in itself. Natural disasters are among the major crisis that most cities in the world have dealt with [2]. Natural disasters have caused more than three million deaths worldwide over the last 25 years and damage of about 23 billion dollars. Meanwhile, the earthquake is one of the most common incidents that occur around the world and has been reported to be the deadliest event in the world in 2001. Iran is ranked among the 10 most accident-prone countries in the world, and the earthquake is responsible for the highest human loss rate in this country. Earthquake zone is spread around $90 \%$ of the Iranian territory [3].

Isfahan is located in the Sanandaj-Sirjan earthquake zone and therefore, it is an earthquake-prone city. The best possible management approach used in critical conditions (like earthquake incidents) is highly dependent on factors such as the severity of the crisis (like the intensity of the earthquake) or the severity of the accident (the extent of damage) and the time of the incident [4]. One of the crisis management solutions for facing the damages and losses caused by the natural disasters including earthquakes in urban settlements is to pay attention to the condition and activity status of the relief stations and their access routes to the damaged areas. The major arterial roads are considered as the networks developed all over the city in order to connect the habitats and the desired points in various city areas. They guarantee the services essential for the performance and survival of the communities including their transportation, energy and communications needs. Meanwhile, role of the road network and location of the relief stations could not be underestimated.

A literature review on the role of urban roads in crisis management revealed that in most conducted studies, after determining the weighted average of the considered measures and sub-measures, the same value was assigned to a road (a street or an avenue) regardless of the different flexibility of their different parts. This was attributed to the fact that in most cases, when only one section of the road was blocked following an earthquake; this led to the inefficiency of the whole road [5].

On the other hand, medical centers are among the most important facilities, which directly contribute to the health status of the people and the society. Having a quick, on-time and inexpensive access to these centers in each condition is very crucial for each community in the city. Nowadays, these centers constitute a major proportion of health organizations' resources [6].

There are some experiences of recent earthquakes in Iran, e.g., the East Azerbaijan earthquake in 2012, the Bushehr earthquake in 2013, the Ilam earthquake in 2014, and the of Khorasan province earthquake in 2017. According to the reports published following recent earthquakes, the operation and services of some hospitals were not available or there were a lot of problems associated with their operations.

As some examples, we could refer to the destruction of Harris Hospital in the Azerbaijan province, the Borazjan Hospital in Bushehr and the Sarpol-e-Zahab Shohada Hospital in the recent earthquake that occurred in Kermanshah [7]. Therefore, it is very important to study the status of the relief stations as well as the access roads of these stations to the incident areas for reducing the human loss and providing the injured individuals with the prompt and on-time relief actions. Development of concepts to identify appropriate emergency care locations and their allocation to emergency treatments could be a key factor for resolving the majority of problems and difficulties that the medical system is currently dealing with. Problems including the lack of accessibility or poor accessibility of the injured persons to these centers and establishment of medical centers in inappropriate places, which can lead to non-compensable personal and social damages to the individual and impose the heavy costs to the health organizations. In this respect, the health care and medical centers, especially hospitals, have a major political, social, economic and therapeutic status in society [8].

\section{Positioning}

Retzlaffet al. (2004) have studied the efficiency status of the medical and health centers in the USA and introduced some solutions to have a better technical performance with the consideration of existing resources. In their opinion, increasing the current funding allocations is not always essential; and so they used a Data Envelopment Analysis Method for this purpose [9]. Kontodimopoulos et al. (2006) studied the correlation of the balance between the efficiency of services and the equity 
subject in the case of accessibility to the medical centers. They used a Data Envelopment Analytical model and evaluated their developed model in Greece, based on the validation data [10]. Klimberg and Ratick (2008) introduced an allocation-positioning model in their study, by setting two cost objective functions using Data Envelopment Analysis [11]. In another study, Vahidnia et al. (2009) studied the positioning of the hospitals using the decision-making models. They used the combination of fuzzy hierarchy process analysis method and Arc GIS software for selection of the best position for the construction of hospital [12]. Further on, Sohn and Choi (2014) have studied the long-term efficiency and quality of the services provided in the hospitals of South Korea. They proposed methods to reach the efficiency and high quality of medical services at the same time [13].

\section{Vulnerability of the urban structure and its street network}

Some studies have been carried out in Iran and other countries to identify the vulnerability criteria of the urban streets against the widening, modifying the vulnerable roads and addressing the relief and survival routes. Jafari et al. (2006) have studied the analysis of structural status of the different regions in Tehran (with regard to the official statistics of the country). The development criteria, vulnerability and structural strength of the building have been investigated in their research. Furthermore, the regions have been classified based on their resistance and vulnerability against the potential risks and eventually, some solutions have been recommended for prevention, preparation of proper planning and crisis management methods in emergency cases [3]. Safari et al. (2008) investigated the major arterial streets of the Ilam City and determined the strengths and weakness points of the road network in this city, using the SWOT (Strengths-Weaknesses-Opportunities-Threats) model, and recommended some solutions to reduce the weakness points and exploit the strengths [14].

Kamelifar (2012) has evaluated the vulnerability of the roads in district 1 of the Tabriz City and investigated this district in terms of the vulnerability of its arterial road network and relief and survival status, following the occurrence of an earthquake. He concluded that vulnerability of the major arterial roads affects the relief operation and therefore, recommended some solutions to resolve this issue [15].

Ahadinejad et al. (2016) in their study evaluated the vulnerability of the urban road network in the district 1 of Tabriz City and proposed plans for its improvement. They used a descriptive-analytical method with crisis management approach in their study and validated the selected criteria using the Delphi method. The final results showed that the vulnerability of the road network in the studied district (except that of newly developed neighborhoods) was more than average (mostly high and very high). Vulnerability of the road network was more pronounced in the informal settlement neighborhoods, which requires more attention in improvement [16].

Nojima and Sugito (2000) developed a simple model for evaluation and simulation of the transportation network of highways in post-earthquake conditions. The model was a combination of the Monte Carlo simulation method and the modified incremental allocation method, in which the first case outlines the vulnerability of the transport network, and the latter indicates the traffic situation in each mode of vulnerability [17]

Yawkesiet al. (2004) examined the performance functions of street networks in earthquake conditions as well as the interactions between its components. They also presented a comprehensive research methodology about the impact of the interaction between the urban street network system components [18]. Kermanshah and Derrible (2016) introduced a geographical evaluation and multi-criteria vulnerability method to determine the effects of severe earthquakes on the road networks on a quantitative basis. They constructed the geological landslide maps to determine the earthquake-prone areas using GIS. They also recommended some solutions for planning travel demands during the earthquake and the effect of severe earthquake on the network [19].

Considering the above researches, it could be said that the majority of studies conducted so far in the field of crisis relief, have focused on the positioning of the new hospitals, while other issues including the existing conditions of the hospitals and relief centers, their service quality in crisis conditions and their accessibility to the incident areas have not received sufficient attention. Therefore, in this study the vulnerable city areas and current situation of the relief centers located in the Isfahan city center have been studied. Furthermore, a methodology to determine the minimum access route from the active stations to the incident-prone traffic zones is proposed.

\section{Materials and Methods}

The central area of Isfahan has the highest population density in comparison with other areas of this city and a large proportion of daily traffic passes through this area. In terms of urban structure, this area comprises old and historical city and about $70 \%$ of the city relief centers 
are located in this area. Therefore, the aim of selection of this area was to reduce the human fatality rate in this area, considering its high population density, and a risk assessment of major street network located in this area. The research method is a combination of documentary, descriptive and analytical methods. Considering the objectives of this research, the information required from major streets (e.g. major and minor arterial streets and some major local streets) located in the districts 1, 3 and parts of surrounding districts were gathered. The information was collected through detailed information published by the "General Population and Housing Census," information extracted from the 1:2000 scaled map of Isfahan, detailed and comprehensive master plans of the city of Isfahan, and other sources.

\section{Results}

Results of the study were obtained via using Arc GIS, Transcad and Excel software and also the Analysis of Hierarchical Process (AHP) model, via using the Expert Choice software, to weigh the criteria, determine the vulnerability of urban structure and the efficiency of the major streets located in this area.

The paired-comparison method has been used in this study to determine the weight of measures in AHP method. The paired-comparison method, used in this study is one of the most widely used and reliable methods due to its strong theoretical basis, ease of application, validity and the accuracy of its results.

In each study, it is essential to select the criteria proportional to the objectives, considering the viewpoints of the experts. The main objectives of this study were to provide relief and reduce the human fatality rate following an earthquake, so some criteria such as construction density and population density are of great importance. Also the distance from the fault location, life time and type of the buildings are some of the other important criteria that have previously been considered for vulnerability studies [20]. On the other hand, the degree of confinement criterion (ratio of the height of the wall to the width of the road) and land use along the road are influential factors for determination of the degree of vulnerability of a road to the risk of destruction following an earthquake. These criteria have also been used in most of the studies conducted in relief studies. Results of weighing the selected criteria using AHP approach is shown in Table 1.

The earthquake vulnerability zoning map of the studied area, shown in Figure 1, was then obtained through using the criteria weights as input data in the Arc GIS software.

\section{Discussion}

The study area covered 94 out of 321 total traffic zones of the Isfahan City, which comprises 186 urban traffic

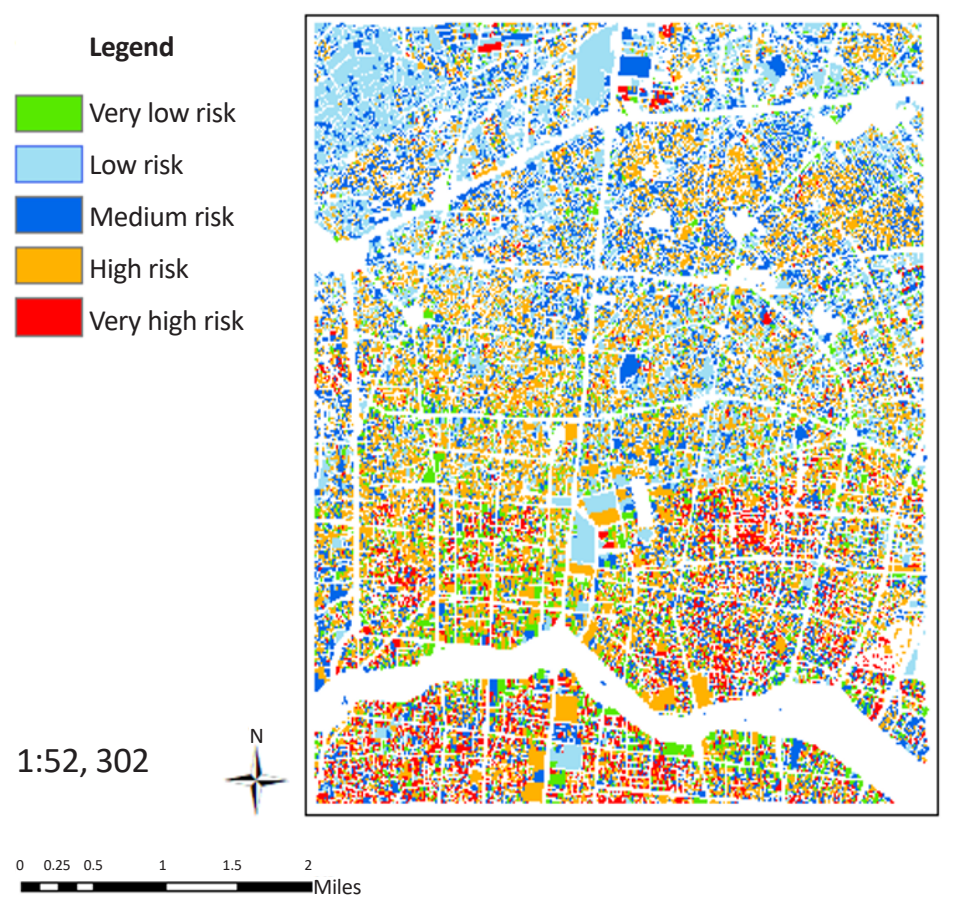

Figure 1. Earthquake vulnerability zoning map of the investigated area 
Table 1. Calculated weight factors for the selected criteria using AHP method

\begin{tabular}{|c|c|c|}
\hline Criteria & Building Type & Weight Factor \\
\hline \multirow{5}{*}{ Building quality } & Concrete-steel & 0.05 \\
\hline & Metal-brick & 0.11 \\
\hline & Brick-adobe & 0.24 \\
\hline & Wooden-adobe & 0.28 \\
\hline & Adobe & 0.32 \\
\hline \multirow{5}{*}{ Building age } & $0-10$ & 0.10 \\
\hline & $10-20$ & 0.18 \\
\hline & & \\
\hline & $20-30$ & 0.32 \\
\hline & $>30$ & 0.40 \\
\hline \multirow{7}{*}{ Population density } & $<50$ & 0.02 \\
\hline & $50-100$ & 0.06 \\
\hline & $100-150$ & 0.09 \\
\hline & $150-200$ & 0.13 \\
\hline & $200-250$ & 0.16 \\
\hline & $250-300$ & 0.24 \\
\hline & $>300$ & 0.29 \\
\hline \multirow{7}{*}{ Building density } & $15-50$ & 0.06 \\
\hline & $50-75$ & 0.08 \\
\hline & $75-100$ & 0.13 \\
\hline & & \\
\hline & $100-150$ & 0.138 \\
\hline & $150-250$ & 0.24 \\
\hline & $250-300$ & 0.31 \\
\hline \multirow{5}{*}{ Land use } & Very low risk & 0.04 \\
\hline & Low risk & 0.10 \\
\hline & Medium risk & 0.16 \\
\hline & High risk & 0.29 \\
\hline & Very high risk & 0.41 \\
\hline \multirow{6}{*}{ Distance from fault (m) } & $<1000$ & 0.06 \\
\hline & $1000-2000$ & 0.08 \\
\hline & $2000-4000$ & 0.13 \\
\hline & $4000-6000$ & 0.138 \\
\hline & $6000-8000$ & 0.24 \\
\hline & $8000-10000$ & 0.31 \\
\hline
\end{tabular}


Table 2. Details of the vulnerability variation of high risk or high vulnerable zones, requiring emergency services within the shortest time

\begin{tabular}{|c|c|c|c|c|c|c|c|}
\hline & Zone Number & $\begin{array}{l}\text { Very Low Risk Area } \\
\qquad\left(\mathrm{m}^{2}\right)\end{array}$ & $\begin{array}{l}\text { Low Risk } \\
\text { Area }\left(\mathrm{m}^{2}\right)\end{array}$ & $\begin{array}{c}\text { Medium } \\
\text { Risk Area } \\
\left(\mathrm{m}^{2}\right)\end{array}$ & $\begin{array}{l}\text { High Risk } \\
\text { Area }\left(\mathrm{m}^{2}\right)\end{array}$ & $\begin{array}{c}\text { Very High } \\
\text { Risk Area } \\
\left(\mathrm{m}^{2}\right)\end{array}$ & $\begin{array}{l}\text { Total Area } \\
\left(\mathrm{m}^{2}\right)\end{array}$ \\
\hline \multirow{2}{*}{1} & 23 & 23085 & 7749 & 65142 & 87752 & 75011 & 258739 \\
\hline & Area (\%) & 8.92 & 2.99 & 25.18 & 33.92 & 28.99 & 100 \\
\hline \multirow{2}{*}{2} & 118 & 10044 & 25294 & 20216 & 61621 & 126749 & 243924 \\
\hline & Area (\%) & 4.12 & 10.37 & 8.29 & 25.26 & 51.96 & 100 \\
\hline \multirow{2}{*}{3} & 119 & 46911 & 14124 & 47705 & 55778 & 109626 & 274144 \\
\hline & Area (\%) & 17.11 & 5.15 & 17.40 & 20.35 & 39.99 & 100 \\
\hline \multirow{2}{*}{4} & 120 & 29648 & 3887 & 131969 & 189544 & 115273 & 470321 \\
\hline & Area (\%) & 6.30 & 0.83 & 28.06 & 40.30 & 24.51 & 100 \\
\hline \multirow{2}{*}{5} & 121 & 6842 & 4632 & 123161 & 56936 & 60854 & 252425 \\
\hline & Area (\%) & 2.71 & 1.84 & 48.79 & 22.56 & 24.11 & 100 \\
\hline \multirow{2}{*}{6} & 122 & 2431 & 9860 & 6933 & 38969 & 182613 & 240806 \\
\hline & Area (\%) & 1.01 & 4.09 & 2.88 & 16.18 & 75.83 & 100 \\
\hline \multirow{2}{*}{7} & 123 & 26851 & 21548 & 69268 & 170988 & 123908 & 412563 \\
\hline & Area (\%) & 6.51 & 5.22 & 16.79 & 41.45 & 30.03 & 100 \\
\hline \multirow{2}{*}{8} & 132 & 20684 & 18821 & 77001 & 91210 & 96496 & 304212 \\
\hline & Area (\%) & 6.80 & 6.19 & 25.31 & 29.98 & 31.72 & 100 \\
\hline \multirow{2}{*}{9} & 133 & 51007 & 53205 & 118095 & 145055 & 233996 & 601358 \\
\hline & Area (\%) & 8.48 & 8.85 & 19.64 & 24.12 & 38.91 & 100 \\
\hline \multirow{2}{*}{10} & 136 & 45868 & 62924 & 117300 & 148027 & 178684 & 552803 \\
\hline & Area (\%) & 8.30 & 11.38 & 21.22 & 26.78 & 32.32 & 100 \\
\hline
\end{tabular}

Hilealth in

Emergencies and |D] isasters [Oluarterly

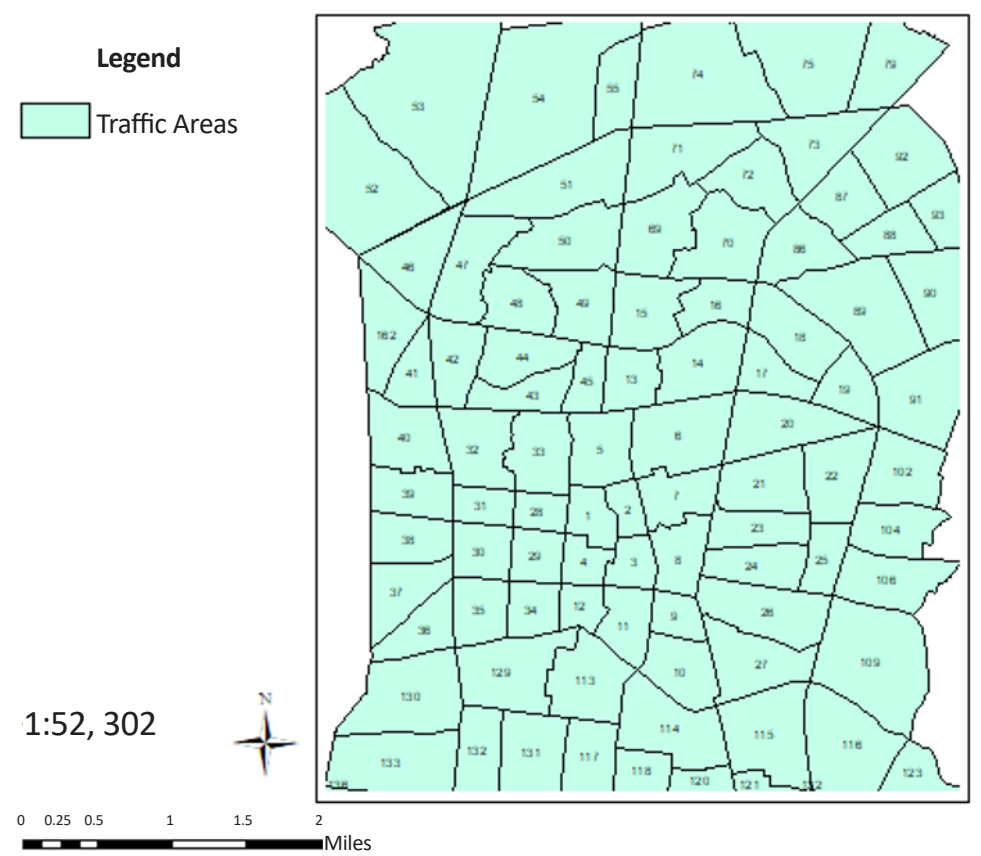

Figure 2. Traffic zoning of the study area 


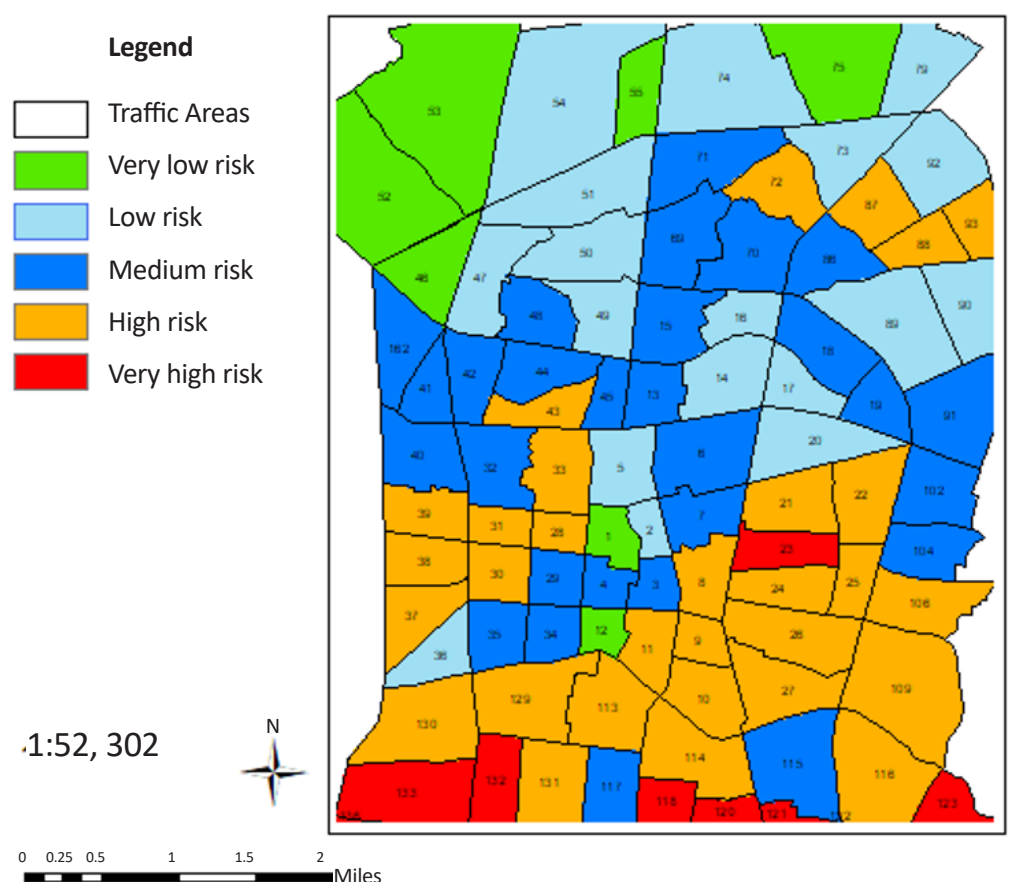

Hlealth in

Emergencies and |D]isasters [Oluarterly

Figure 3. The earthquake vulnerability zoning map of the study area in accordance with the traffic zones

zones and 135 sub-urban zones (Figure 2). The objective of this study was to identify the safe and high-risk traffic zones and investigating the appropriate locations for the relief stations in addition to identify the risk-prone residential areas. Furthermore, by identifying the ac- tive stations, the shortest path is specified for providing emergency services to the vulnerable residential areas. The final objective of this study was to reduce the relief time and to utilize the maximum capacity of emergency centers to minimize the human fatality rate.

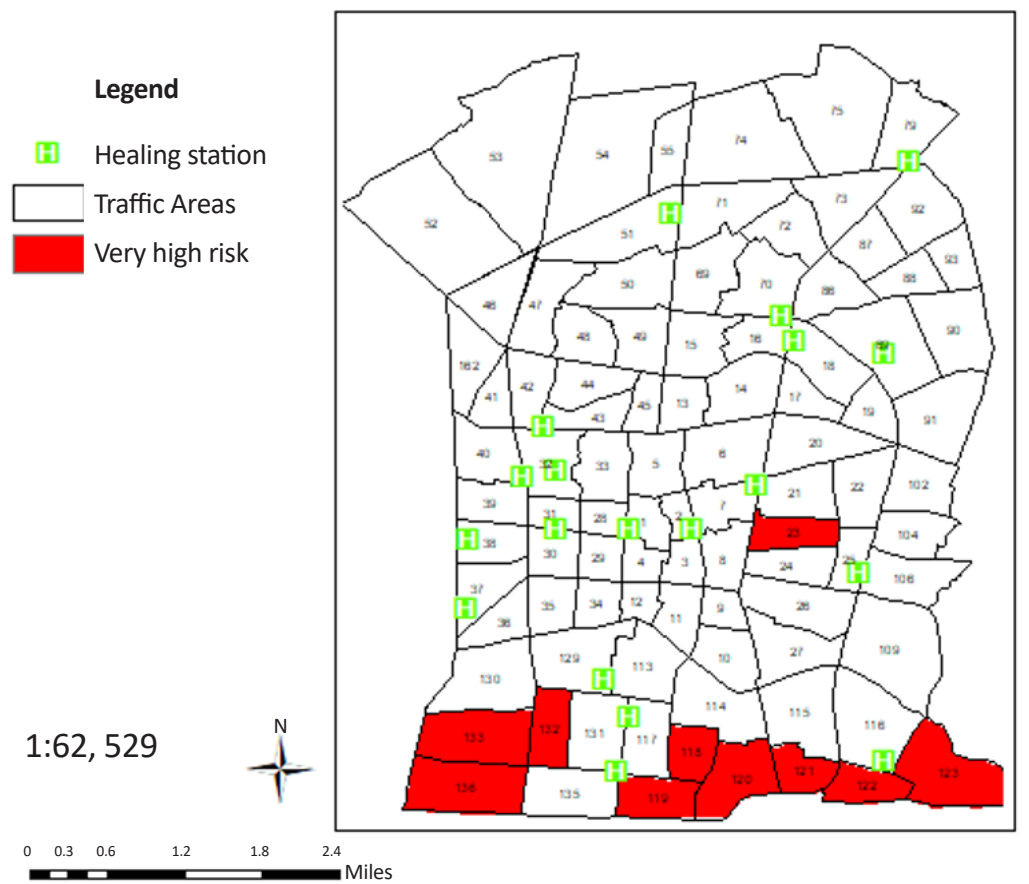

Health in

Emergencies and |D]isasters [O]uarterly

Figure 4. Emergency relief centers within the range of 1000 meters from the vulnerable zones 


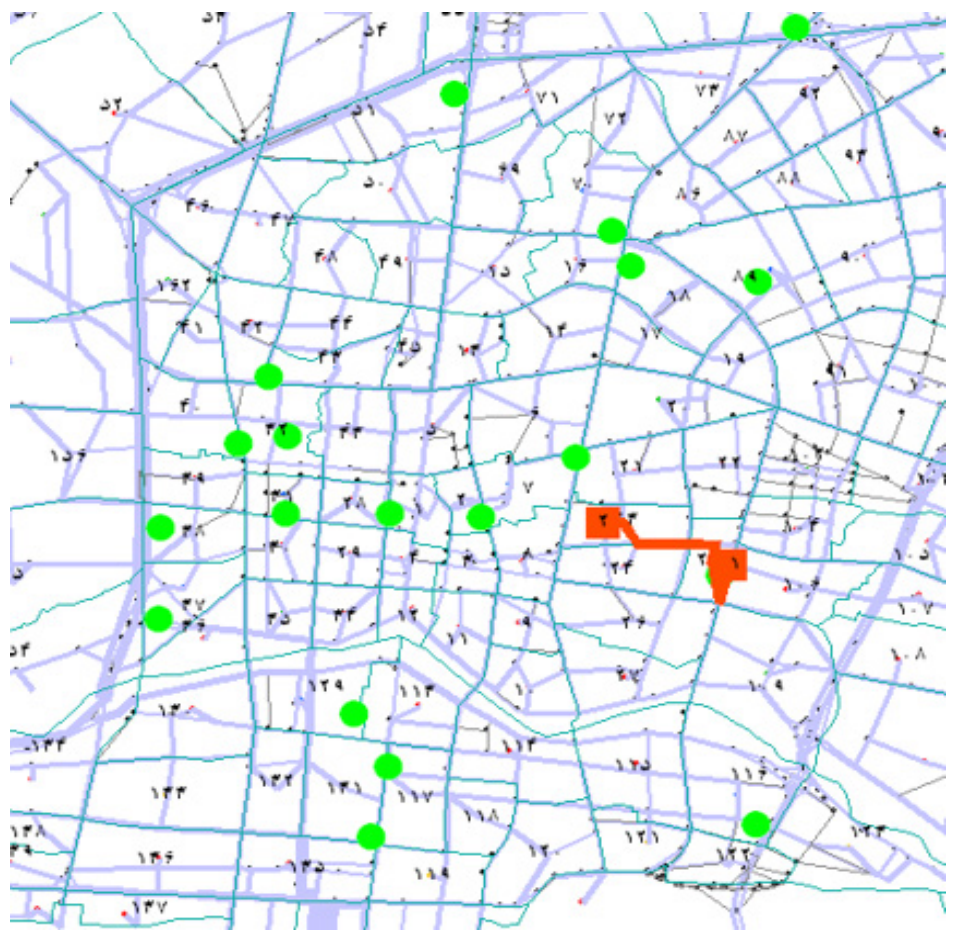

Figure 5. Optimal route from Sadoughi Hospital to traffic area no. 23

According to the Figure 3 that was prepared based on the predominant risk level observed in each zone, it could be concluded that regions $12,1,75,55,53,52$ and 46 have an acceptable status on the basis of the selected criteria. This means that the risk level in these zones is small. In contrast, the zones 132, 133, 136, 118, 119, $120,121,122,123$ and 23 are highly vulnerable. The status of emergency relief centers in the range of 1000 meters distance from these zones is also shown in Figure 4. Figure 4 also shows the earthquake vulnerability zoning map of the study area specified in accordance with the traffic zones. Table 2 shows the vulnerability details of high-risk areas versus their measured risk levels.

The shortest travel time under crisis conditions for transfer of emergency vehicles to the vulnerable zones was also determined using the "Equilibrium Traffic Assignment algorithm" in Transcad software and presented in Table 3.

In the case of lack of adequate capacity of each medical center to accommodate all referred injured people, it is possible to use the next closest relief centers. Figure 5

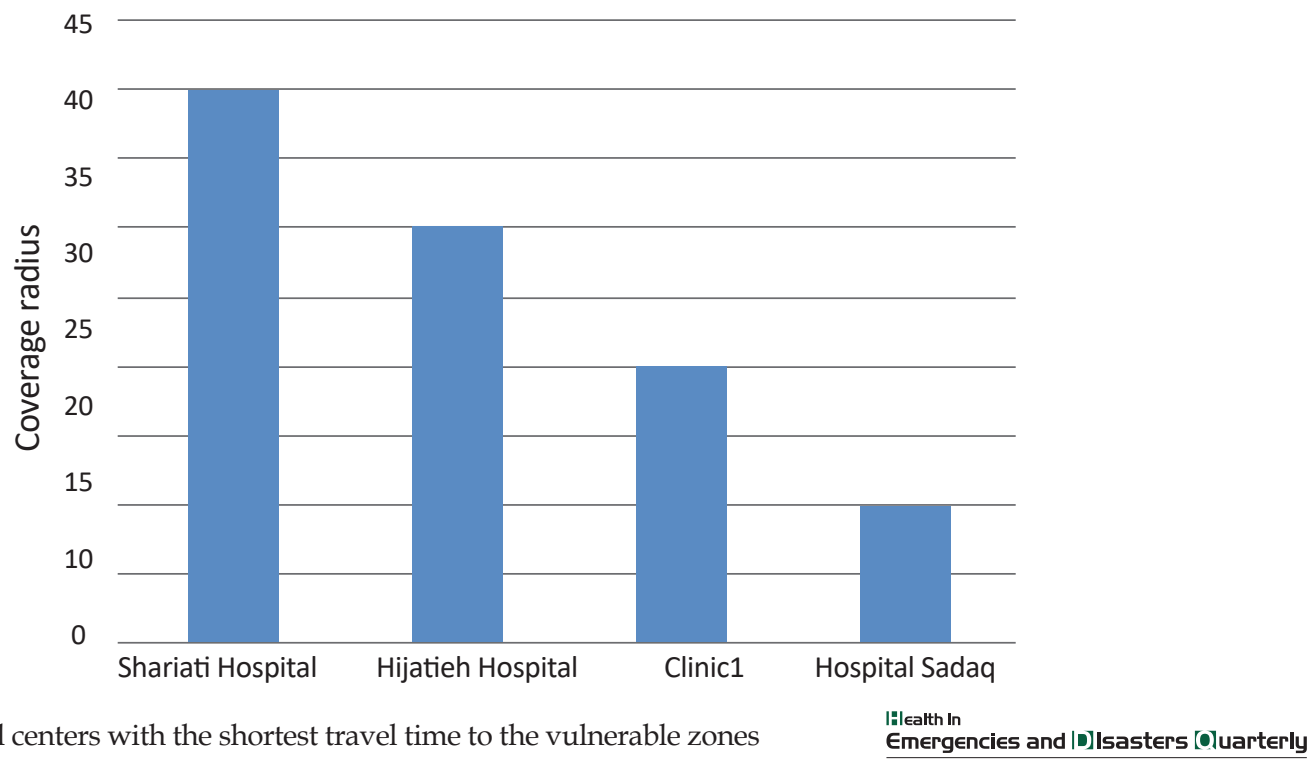


Table 3. The shortest trip time from medical stations to accidental areas using Transcad software

\begin{tabular}{|c|c|c|c|c|c|c|c|c|}
\hline $\begin{array}{l}\text { Healing Sta- } \\
\text { tion Name }\end{array}$ & $\begin{array}{c}\text { Risk Zone } \\
\text { Number }\end{array}$ & $\begin{array}{l}\text { Travel Time } \\
\text { in Crisis } \\
\text { Mode (Min) }\end{array}$ & $\begin{array}{l}\text { Healing Station } \\
\text { Name }\end{array}$ & $\begin{array}{c}\text { Risk Zone } \\
\text { Number }\end{array}$ & $\begin{array}{c}\text { Travel } \\
\text { Time in } \\
\text { Crisis Mode } \\
\text { (Min) }\end{array}$ & $\begin{array}{l}\text { Healing } \\
\text { Station } \\
\text { Name }\end{array}$ & $\begin{array}{c}\text { Risk } \\
\text { Zone } \\
\text { Number }\end{array}$ & $\begin{array}{c}\text { Travel Time in } \\
\text { Crisis Mode } \\
\text { (Min) }\end{array}$ \\
\hline Sina & 23 & 27.06 & Ahmadiyeh & 120 & 36.86 & Feiz & 123 & 77.39 \\
\hline Sina & 118 & 28.17 & Ahmadiyeh & 121 & 57.29 & Feiz & 132 & 36.45 \\
\hline Sina & 119 & 28.48 & Ahmadiyeh & 122 & 78.39 & Feiz & 133 & 43.37 \\
\hline Sina & 120 & 29.57 & Ahmadiyeh & 123 & 69.17 & Feiz & 138 & 53.47 \\
\hline Sina & 121 & 50.00 & Ahmadiyeh & 132 & 27.27 & Specialized & 23 & 49.27 \\
\hline Sina & 122 & 70.97 & Ahmadiyeh & 133 & 34.19 & Specialized & 118 & 70.59 \\
\hline Sina & 123 & 61.75 & Ahmadiyeh & 138 & 44.29 & Specialized & 119 & 70.90 \\
\hline Sina & 138 & 37.83 & $\begin{array}{c}\text { Seyyed Al Sho- } \\
\text { hada }\end{array}$ & 119 & 25.58 & Specialized & 122 & 85.56 \\
\hline Ali Asghar & 23 & 23.60 & $\begin{array}{c}\text { Seyyed Al Sho- } \\
\text { hada }\end{array}$ & 120 & 26.67 & Specialized & 123 & 76.33 \\
\hline Ali Asghar & 118 & 29.13 & $\begin{array}{c}\text { Seyyed Al Sho- } \\
\text { hada }\end{array}$ & 121 & 47.09 & Specialized & 132 & 63.22 \\
\hline Ali Asghar & 121 & 50.96 & $\begin{array}{c}\text { Seyyed Al Sho- } \\
\text { hada }\end{array}$ & 132 & 17.08 & Askarieh & 23 & 21.04 \\
\hline Ali Asghar & 122 & 71.93 & $\begin{array}{c}\text { Seyyed Al Sho- } \\
\text { hada }\end{array}$ & 133 & 23.99 & Askarieh & 118 & 48.29 \\
\hline Ali Asghar & 123 & 62.71 & $\begin{array}{c}\text { Seyyed Al Sho- } \\
\text { hada }\end{array}$ & 138 & 34.10 & Askarieh & 119 & 48.60 \\
\hline Ali Asghar & 132 & 21.77 & Center 7 & 23 & 40.09 & Askarieh & 120 & 49.69 \\
\hline Ali Asghar & 133 & 28.69 & Center 7 & 118 & 26.33 & Askarieh & 121 & 70.11 \\
\hline $\begin{array}{l}\text { Javadalae- } \\
\text { meh }\end{array}$ & 119 & 47.61 & Center 7 & 122 & 73.67 & Askarieh & 133 & 47.84 \\
\hline $\begin{array}{c}\text { Javadalae- } \\
\text { meh }\end{array}$ & 120 & 48.70 & Center 7 & 123 & 64.45 & Askarieh & 138 & 57.95 \\
\hline $\begin{array}{c}\text { Javadalae- } \\
\text { meh }\end{array}$ & 121 & 69.12 & Center 7 & 132 & 18.14 & Hojatieh & 23 & 17.65 \\
\hline $\begin{array}{c}\text { Javadalae- } \\
\text { meh }\end{array}$ & 122 & 90.09 & Center 7 & 133 & 25.05 & Hojjatieh & 118 & 14.77 \\
\hline $\begin{array}{c}\text { Javadalae- } \\
\text { meh }\end{array}$ & 123 & 80.87 & Center 7 & 138 & 35.16 & Hojjatieh & 119 & 15.80 \\
\hline $\begin{array}{c}\text { Javadalae- } \\
\text { meh }\end{array}$ & 132 & 39.94 & Kashani & 23 & 32.12 & Hojjatieh & 120 & 16.17 \\
\hline $\begin{array}{l}\text { Javadalae- } \\
\text { meh }\end{array}$ & 133 & 46.85 & Kashani & 118 & 40.64 & Hojjatieh & 121 & 17.69 \\
\hline $\begin{array}{c}\text { Javadalae- } \\
\text { meh }\end{array}$ & 138 & 56.96 & Kashani & 119 & 40.95 & Hojjatieh & 122 & 23.53 \\
\hline $\begin{array}{l}\text { Zahraye } \\
\text { Marzie }\end{array}$ & 23 & 16.85 & Kashani & 120 & 42.04 & Hojjatieh & 123 & 14.31 \\
\hline $\begin{array}{l}\text { Zahraye } \\
\text { Marzie }\end{array}$ & 118 & 39.53 & Kashani & 121 & 62.46 & Hojjatieh & 132 & 20.37 \\
\hline $\begin{array}{l}\text { Zahraye } \\
\text { Marzie }\end{array}$ & 119 & 39.84 & Kashani & 122 & 83.57 & Hojjatieh & 133 & 31.15 \\
\hline $\begin{array}{c}\text { Zahraye } \\
\text { Marzie }\end{array}$ & 120 & 40.93 & Kashani & 123 & 74.34 & Hojjatieh & 138 & 42.69 \\
\hline
\end{tabular}




\begin{tabular}{|c|c|c|c|c|c|c|c|c|}
\hline $\begin{array}{l}\text { Healing Sta- } \\
\text { tion Name }\end{array}$ & $\begin{array}{l}\text { Risk Zone } \\
\text { Number }\end{array}$ & $\begin{array}{l}\text { Travel Time } \\
\text { in Crisis } \\
\text { Mode (Min) }\end{array}$ & $\begin{array}{l}\text { Healing Station } \\
\text { Name }\end{array}$ & $\begin{array}{l}\text { Risk Zone } \\
\text { Number }\end{array}$ & $\begin{array}{c}\text { Travel } \\
\text { Time in } \\
\text { Crisis Mode } \\
\text { (Min) }\end{array}$ & $\begin{array}{l}\text { Healing } \\
\text { Station } \\
\text { Name }\end{array}$ & $\begin{array}{c}\text { Risk } \\
\text { Zone } \\
\text { Number }\end{array}$ & $\begin{array}{c}\text { Travel Time in } \\
\text { Crisis Mode } \\
\text { (Min) }\end{array}$ \\
\hline $\begin{array}{l}\text { Zahraye } \\
\text { Marzie }\end{array}$ & 121 & 61.35 & Kashani & 132 & 32.45 & Clinic 1 & 23 & 32.36 \\
\hline $\begin{array}{l}\text { Zahraye } \\
\text { Marzie }\end{array}$ & 122 & 82.32 & Kashani & 133 & 38.90 & Clinic 1 & 118 & 1.26 \\
\hline $\begin{array}{l}\text { Zahraye } \\
\text { Marzie }\end{array}$ & 123 & 73.10 & Kashani & 138 & 38.74 & Clinic 1 & 119 & 2.29 \\
\hline
\end{tabular}

shows an example of optimum path identified for a vulnerable zone using the shortest route method. Using the Table 3, the emergency centers with great importance in providing post-earthquake medical services have been identified and shown in Figure 6. Shariati, Hojatieh, Specialized Clinic No. 1 and Sadoughi hospitals have the best access to the vulnerable zones, each providing the relief services up to its capacity. Using the emergency services, the injured people could be transferred to the mentioned hospitals in the shortest time.

As another example for the application of the results obtained from this study, the status of these four medical centers was examined using the same measures that were used to establish the earthquake vulnerability zoning map. The measures used for these purposes were: the structural properties of the buildings such as life time, quality, number of floors, as well as the population density and the land use density. The final results are shown in Figure 6. Using this analysis, only clinic No. 1 demonstrated an acceptable status, and the other three centers, all located in risk zones, are vulnerable to destruction damages or to face the problems such as blockage of their access roads. This would indicate that, not only these centers will be unable to provide the relief services, but also the relief center itself will be in crisis.

\section{Conclusion}

This study indicated the possibility of using a combination of Analytical Hierarchy Process (AHP), ArcGIS and Transcad software to identify the factors contributing to the vulnerability of infrastructures located in the study area, the relative importance of these factors to each other, identification of high risk zones, identification of appropriate medical centers for relief purposes and also the service capability of these centers in crisis conditions. For this case study, the recommended methodology was examined for 94 traffic zones located in the Isfahan city center. The results indicated potential successful applica- tion of this methodology. The results obtained from this case study application with the proposed method for the city of Isfahan could be outlined as follows:

The physical quality of the buildings and infrastructure is not adequate to determine the vulnerability of the traffic zones and other measures such land use density, population density, the type and quality of buildings and their lifetime are also highly effective; The secure traffic zones have been located in the northern areas of the study zone, while the risk-prone areas are located in the southern side. Following an earthquake, it is anticipated that a rather huge traffic wave in the network for evacuation and temporary accommodation will be generated; The results indicated that traffic zones no. 132, 133, 136, 118, 119, 120, $121,122,123$ and 23 have very high vulnerability levels; High-risk traffic zones are located in a close proximity; so they may interrupt the relief services; The vulnerability of the district 3 is very high. This can be attributed to the old and historical buildings and also, narrow and rather long streets surrounded by high-density buildings in this area; Some relief and medical centers such as emergency centers in Hojatieh and Amir al Momenin hospitals are also at risk. This is due to their inappropriate position or location in narrow and vulnerable streets, as there are potential closures of access roads to them.

It is recommended to retrofit the hospitals, especially those identified as crucial relief centers and to provide them with more relief equipments. In addition, their nearby access streets should be extended and widened to create a relief corridor in crisis times and the buildings in these areas should be strengthened as well.

\section{Acknowledgments}

The present paper is extracted from a master dissertation of the first Author at Department of Civil Engineering, Faculty of Engineering, Yazd University, and funded by the Municipality of Isfahan, No. 121/96/2226. 


\section{Conflict of Interest}

The authors declared no conflicts of interest.

\section{References}

[1] Yang L, Jones BF, Yang Sh. A fuzzy multi-objective programming for optimization of fire station locations through genetic algorithms. European Journal of Operational Research. 2007; 181(2):903-15. doi: 10.1016/j.ejor.2006.07.003

[2] Alexander DE. Principles of emergency planning and management. Oxford: Oxford University Press on Demand; 2002.

[3] Avazeh A, Jafari N. [Investigating the capabilities and limitations of educational hospitals of Zanjan university of medical sciences in crisis management (Planning, structural and non-structural) (Persian)]. Paper presented at the National Conference on Crisis Management Development Facilitation In Accidental Accidents. 20-21 August 2006; Zanjan, Iran.

[4] Zangi Abadi A, Mohammadi J, Safaee H, Rahmati S. [Vulnerability indicators assessment of urban housing against the earthquake hazard case study: Isfahan housing (Persian)]. Geography and Development. 2008; 6(12):61-79. doi: 10.22111/ GDIJ.2008.1243

[5] Ahmadnezhad Roosti, M., Rostaei, Sh., Kamilifar, M. J. [Evaluation of the vulnerability of urban road network against earthquake with crisis management approach (Case study: District 1 of Tabriz city) (Persian)]. Geographical Information Quarterly (Sepehr). 2015; 24(95):50-37.

[6] Aeinparast A. [Methods of determining costs of patients based on diagnosis related group (DRG) (Persian)]. Journal of Health Administration. 1998; 2(3):94-105.

[7] Merikhi N. [Necessity and Possibility of Seismic Design and Retrofitting of Non-Acoustic Components of Buildings by Looking at Recent Earthquakes in the Country, and the Guidelines for Designing Existing Civil Construction (Persian)]. Retrofitting \& Rehabilitation. 2014; 31:74-8.

[8] Sedghiyani E. [Hospitals in future (Persian)]. Journal of Health Administration. 1998; 2(2):1-14.

[9] Retzlaff Roberts D, Chang CF, Rubin RM. Technical efficiency in the use of health care resources: A comparison of OECD countries. Health Policy. 2004; 69(1):55-72. doi: 10.1016/j. healthpol.2003.12.002

[10] Kontodimopoulos N, Nanos P, Niakas D. Balancing efficiency of health services and equity of access in remote areas in Greece. Health Policy. 2006; 76(1):49-57. doi: 10.1016/j. healthpol.2005.04.006

[11] Klimberg RK, Ratick SJ. Modeling Data Envelopment Analysis (DEA) efficient location/allocation decisions. Computers \& Operations Research. 2008; 35(2):457-74. doi: 10.1016/j.cor.2006.03.010

[12] Vahidnia MH, Alesheikh AA, Alimohammadi A. Hospital site selection using fuzzy AHP and its derivatives. Journal of Environmental Management. 2009; 90(10):3048-56. doi: 10.1016/j.jenvman.2009.04.010
[13] Sohn M, Choi M. Association between efficiency and quality of health care in South Korea long-term care hospitals: Using the data envelopment analysis and matrix analysis. Journal of Korean Academy of Nursing. 2014; 44(4):418. doi: 10.4040/jkan.2014.44.4.418

[14] Safari F. [Planning and management of urban crisis with emphasis on vital arteries (Case study: Ilam city) (Persian)] [Master's Thesis]. Isfahan: Isfahan University; 2008.

[15] Kamali Far MJ. [Evaluation of urban road network against earthquake with crisis management approach (Case study: District 1 of Tabriz city) (Persian)] [Master's Thesis]. Zanjan: Zanjan University; 2012.

[16] Kamelifar MJ, Rustei S, Ahadnejad M, Kamelifar Z. The assessment of road network vulnerability in formal and informal (slum) urban tissues to earthquake hazards with crisis management approach (Case study: Zone 1 Tabriz). Journal of Civil Engineering and Urbanism. 2013; 3:380-5

[17] Nojima N, Sugito M. Simulation and evaluation of postearthquake functional performance of transportation network. Paper presented at the $12^{\text {th }}$ World Conference on Earthquake Engineering. 30 January-4 February 2000; Auckland, New Zealand.

[18] Yao B, Xie L, Huo E. Study effect of lifeline interaction under seismic conditions. Paper presented at the $13^{\text {th }}$ World Conference on Earthquake Engineering. 1-6 August 2004; Vancouver, British Columbia, Canada.

[19] Kermanshah A, Derrible S. A geographical and multicriteria vulnerability assessment of transportation networks against extreme earthquakes. Reliability Engineering \& System Safety. 2016; 153:39-49. doi: 10.1016/j.ress.2016.04.007

[20] Sa'idian Z. [Evaluation and evaluation of critical transport arteries in the event of an earthquake: District 3 of Isfahan (Persian)] [Master's Thesis]. Yazd: Yazd University; 2014. 